\title{
The Mosaic porcine bioprosthesis: Role of age on clinical performance in aortic position
}

\author{
Friedrich-Christian Rieß, MD, ${ }^{\mathrm{a}}$ Ralf Bader, MD, ${ }^{\mathrm{a}}$ Eva Cramer, MD, ${ }^{\mathrm{a}}$ Lorenz Hansen, MD, ${ }^{\mathrm{a}}$ \\ Sandra Schiffelers, ${ }^{\mathrm{b}}$ Jürgen Wallrath, ${ }^{\mathrm{b}}$ and Gunter Wahl, MD ${ }^{\mathrm{a}}$
}

\begin{abstract}
Background: The Mosaic bioprosthesis is a third-generation stented porcine bioprosthesis combining physiologic fixation and $\alpha$-amino oleic acid antimineralization treatment to improve durability and hemodynamic function. This single-center study reports on the performance of the Mosaic bioprosthesis in patients 65 years of age or less and patients older than 65 years at implantation.
\end{abstract}

Methods: Between 1994 and 1999, 88 younger patients (mean age, 58 years) and 167 older patients (mean age, 72 years) were enrolled in this prospective nonrandomized clinical trial. Follow-up visits were performed after 30 days, 6 months, and annually. Cumulative follow-up was 751 patient-years in the younger group and 1223 patient-years in the older group.

Results: Mean systolic gradient increased significantly to 17.0 and $14.7 \mathrm{~mm} \mathrm{Hg}$ in younger and older patients, respectively, at their latest follow-up $(P<.001)$. Effective orifice area values decreased significantly to 1.8 and $1.6 \mathrm{~cm}^{2}(P<.001)$. Overall, effective orifice area values were significantly higher in younger patients $(P<.001)$. Transvalvular regurgitation increased over time $(P<.001)$ but remained mild or less in more than $95 \%$ of the patients. Freedom from adverse events at latest follow-up in younger and older patients, respectively, were as follows: structural valve deterioration, $85.7 \%$ and $86.2 \%(P<.05)$; endocarditis, $87.5 \%$ and $98.5 \%$ $(P<.01)$; valvular thrombosis, $98.8 \%$ and $97.1 \%$ (not significant); and explantation, $68.9 \%$ and $77.9 \%(P<.01)$.

Conclusions: Hemodynamic performance is similar in both groups. In the younger patients the incidence of structural valve disease, endocarditis, valve-related reoperation, and explantation is higher. The incidence in structural valve deterioration in the younger patients tends to be similar or lower compared with that seen in the literature. (J Thorac Cardiovasc Surg 2011;141:1440-8)

Supplemental material is available online.

Progressive tissue degeneration and calcification lead to structural valve deterioration (SVD) in bioprostheses and suboptimal hemodynamic performance over time. The literature shows that tissue valves implanted in younger patients are more prone to $\mathrm{SVD}^{1-7}$ and have a shorter valve life. ${ }^{1,4,7}$

The Mosaic bioprosthesis is a third-generation stented porcine bioprosthesis that was introduced in 1994. Its

\footnotetext{
From the Albertinen Heart Center, ${ }^{a}$ Hamburg, Germany, and the Medtronic Bakken Research Center, ${ }^{\mathrm{b}}$ Cardiac Surgery Clinical Research Department, Maastricht, The Netherlands.

This study was supported by a grant from Medtronic Bakken Research Center.

Disclosures: Friedrich-Christian Rie $\beta$, Ralf Bader, Eva Cramer, Lorenz Hansen, Sandra Schiffelers, and Gunter Wahl have no commercial interests to disclose. Jürgen Wallrath reports equity ownership in Medtronic, and is a Medtronic employee.

Received for publication Nov 9, 2009; revisions received April 22, 2010; accepted for publication May 20, 2010; available ahead of print Sept 20, 2010.

Address for reprints: Friedrich-Christian Rieß, MD, Albertinen Heart Center, Department of Cardiac Surgery, Suentelstrasse 11 a, 22457 Hamburg, Germany (E-mail: Friedrich-Christian.Riess@albertinen.de).

0022-5223/\$36.00

Copyright @ 2011 by The American Association for Thoracic Surgery doi:10.1016/j.jtcvs.2010.05.052
}

design is based on the Medtronic Hancock II valve. ${ }^{1}$ Technical innovations are incorporated to improve durability and hemodynamic performance. ${ }^{8}$ Features of the Mosaic valve are tissue fixation by means of glutaraldehyde, ${ }^{9}$ predilatation of the porcine aortic root, and zero pressure fixation across the leaflets to preserve natural leaflet morphology. ${ }^{10}$ The tissue is mounted on a lowprofile flexible polymer stent suitable for supra-annular implantation. Furthermore, the Mosaic bioprosthesis is treated with $\alpha$-amino oleic acid that binds to the aldehyde fractions of the glutaraldehyde-preserved porcine tissue by forming Schiff base covalent linkages. The $\alpha$-amino oleic acid process has been shown to reduce porcine valve mineralization of both the leaflets and aortic wall and to improve valve gradients in several animal studies. ${ }^{11-13}$

This single-center study compares the clinical performance, including hemodynamic data, and valve-related morbidity and mortality of the Mosaic bioprosthesis implanted in patients aged 65 years or less with that of patients older than 65 years. Patients were enrolled as part of a US Food and Drug Administration multicenter, prospective, nonrandomized clinical evaluation study that concluded in late 2000. Patient follow-up was continued as part of an ongoing, long-term, post-US Food and Drug Administration approval study. 


\section{Abbreviations and Acronyms \\ $\mathrm{AF} \quad=$ atrial fibrillation \\ EOA = effective orifice area \\ NYHA $=$ New York Heart Association \\ SVD = structural valve deterioration \\ SVG $=$ systolic valve gradient}

\section{MATERIALS AND METHODS \\ Patient Population and Study Design}

Between February 1994 and October 1999, a total of 255 patients requiring aortic valve replacement were enrolled in this prospective nonrandomized study: 88 patients were 65 years of age or less (mean age, $58 \pm 8$ years; range, 23-65 years), and 167 patients were older than 65 years (mean age, $72 \pm 4$ years; range, 66-82 years). Further demographic data are summarized in Table 1. Patients requiring replacement of more than 1 valve or who had a pre-existing prosthetic heart valve in another position were excluded from the study, as were patients who had to undergo a reoperation of the study valve.

The study was approved by the institutional ethics committee, and all patients provided informed consent before participation.

\section{Surgical Technique and Anticoagulation Management}

During surgical intervention, standard cardioplegia, cardiac arrest, and crystalloid or modified blood cardioplegia were applied. Mosaic bioprostheses were implanted in the supra-annular position with felt-armed single stitches. All patients received unfractionated heparin by means of intravenous infusion during the first 24 hours after implantation, followed by subcutaneous injections until complete mobilization. For 3 months postoperatively, $36(41 \%)$ younger patients and $59(35 \%)$ older patients received phenprocoumon with a target international normalized ratio range of 2.5 to 3.0. Indications for phenprocoumon treatment were permanent atrial fibrillation (AF) and severely impaired left ventricular ejection fraction $(<30 \%)$.

\section{Follow-up}

Clinical performance and valve-related morbidity and mortality of the Mosaic bioprosthesis were assessed at the early follow-up interval (before discharge or within 30 days after implantation), the late interval (3-6 months after implantation), 1-year follow-up (11-14 months after implantation), and annually thereafter. The examination included an interview, a 12-lead electrocardiogram, and a laboratory check for hemolysis. Furthermore, transthoracic echocardiographic analysis was performed for all patients. The mean systolic valve gradient (SVG) was calculated by using the long form of the Bernoulli equation, and the effective orifice area (EOA) was calculated by using the continuity equation. Valve-related morbidity and mortality were classified and reported according to the guidelines of the Society of Thoracic Surgeons, the American Association of Thoracic Surgery, and the European Association of Cardio-Thoracic Surgery. ${ }^{14}$

Data are current until June 27, 2008. This provides a cumulative follow-up of 751 patient-years in the younger group (median, 9.8 years; maximum, 14.0 years) and 1223 patient-years in the older group (median, 7.9 years; maximum, 13.4 years). Twelve (14\%) patients in the younger group and $55(33 \%)$ patients in the older group were lost to follow-up. Reasons for loss to follow-up are as follows: patient refuses further participation ( $\mathrm{n}=2$ vs $\mathrm{n}=20)$, unknown location of patient $(\mathrm{n}=8$ vs $\mathrm{n}=30$ ), patient moved ( $\mathrm{n}=2$ vs $\mathrm{n}=3$ ), and unknown reasons $(\mathrm{n}=0$ vs $\mathrm{n}=2)$.
TABLE 1. Characteristics of patients aged 65 years or younger and patients older than 65 years undergoing aortic valve replacement with the Mosaic bioprosthesis

\begin{tabular}{|c|c|c|c|}
\hline & $\begin{array}{c}\leq 65 y \\
(n=88) \\
\end{array}$ & $\begin{array}{c}\geq 65 y \\
(n=167) \\
\end{array}$ & $\begin{array}{c}P \\
\text { value } \\
\end{array}$ \\
\hline \multicolumn{4}{|l|}{ Sex } \\
\hline Male & $66(75.0 \%)$ & $84(50.3 \%)$ & \multirow[t]{2}{*}{$P<0.001$} \\
\hline Female & $22(25.0 \%)$ & $83(49.7 \%)$ & \\
\hline \multicolumn{4}{|l|}{ NYHA classification } \\
\hline Class I & $3(3.4 \%)$ & $1(0.6 \%)$ & \multirow[t]{4}{*}{ NS } \\
\hline Class II & $26(29.5 \%)$ & $48(28.7 \%)$ & \\
\hline Class III & $54(61.4 \%)$ & $96(57.5 \%)$ & \\
\hline Class IV & $5(5.7 \%)$ & $22(13.2 \%)$ & \\
\hline \multicolumn{4}{|l|}{ Cardiac rhythm } \\
\hline Sinus rhythm & $79(89.7 \%)$ & $151(90.4 \%)$ & \multirow[t]{4}{*}{ NS } \\
\hline Atrial fibrillation & $2(2.3 \%)$ & $10(6.0 \%)$ & \\
\hline Heart block & $3(3.4 \%)$ & $3(1.8 \%)$ & \\
\hline Paced rhythm & $4(4.6 \%)$ & $3(1.8 \%)$ & \\
\hline \multicolumn{4}{|l|}{ Valvular lesion } \\
\hline Stenosis & $14(15.9 \%)$ & $29(17.4 \%)$ & \multirow[t]{3}{*}{$P<0.05$} \\
\hline Insufficiency & $20(22.7 \%)$ & $18(10.7 \%)$ & \\
\hline Mixed & $54(61.4 \%)$ & $120(71.9 \%)$ & \\
\hline \multicolumn{4}{|l|}{ Implanted valve size } \\
\hline $19 \mathrm{~mm}$ & $0(0.0 \%)$ & $7(4.2 \%)$ & \multirow[t]{6}{*}{$<.001$} \\
\hline $21 \mathrm{~mm}$ & $7(8.0 \%)$ & $58(34.7 \%)$ & \\
\hline $23 \mathrm{~mm}$ & $29(33.0 \%)$ & $62(37.1 \%)$ & \\
\hline $25 \mathrm{~mm}$ & $41(46.5 \%)$ & $37(22.2 \%)$ & \\
\hline $27 \mathrm{~mm}$ & $9(10.2 \%)$ & $3(1.8 \%)$ & \\
\hline $29 \mathrm{~mm}$ & $2(2.3 \%)$ & $0(0.0 \%)$ & \\
\hline \multicolumn{4}{|l|}{ Concomitant procedures } \\
\hline Coronary artery bypass & $26(29.6 \%)$ & $69(41.3 \%)$ & NS \\
\hline $\begin{array}{l}\text { Ascending aortic } \\
\text { replacement/repair }\end{array}$ & $13(14.8 \%)$ & $18(10.8 \%)$ & NS \\
\hline Aortic root enlargement & $6(6.8 \%)$ & $14(8.4 \%)$ & NS \\
\hline Myotomy/myectomy & $5(5.7 \%)$ & $6(3.6 \%)$ & NS \\
\hline
\end{tabular}

NYHA, New York Heart Association; NS, not significant.

\section{Statistical Analysis}

Statistical analysis was performed with SAS statistical software, version 9.1 (SAS Institute, Inc, Cary, NC). Descriptive statistics are used to characterize data on the patient population, operative data, and follow-up data.

For continuous variables, the number of patients and mean or median, standard deviation, minimum, and maximum values are provided. Differences between age groups were analyzed by using the Student's $t$ test. The effect of age over time was analyzed by using repeated-measures analysis of variance. For categorical variables, the number and percentage of patients are provided. Differences between age groups were analyzed by using Pearson's $\chi^{2}$ or Fisher's exact test. The effect of age over time was analyzed by using logistic regression analysis.

Early morbidity is defined as morbidity occurring within the first 30 days after implantation. Early mortality is defined as mortality occurring within the first 30 days after implantation or occurring more than 30 days after implantation but before hospital discharge. Early adverse event rates are calculated as the number of patients having the event divided by the total number of patients and expressed as a percentage. Late adverse events are summarized by using linearized rates, calculated by dividing the number of late events by the sum of the late patient-years, and expressed as a percentage. Survival analysis with the actuarial Kaplan-Meier method is used to estimate survival and freedom from valve-related adverse events. Peto's formula ${ }^{15}$ is used to calculate standard errors of these estimates. The 
effect of age over time is analyzed by using log-rank testing. Adverse events that occurred during the early and late postoperative periods are included in the analysis.

The preoperative variables, tested for their univariate and multivariate association with the outcomes, include sex, age (per 5-year increase), New York Heart Association (NYHA) class IV, preoperative AF, preoperative current smoker, preoperative active endocarditis, preoperative chronic obstructive pulmonary disease, preoperative obesity, aortic valve lesion (stenosis, insufficiency, or mixed), previous cardiac surgery, and concomitant coronary artery bypass grafting. Multivariate analysis with Cox multivariate regression analysis methodology was conducted to examine risk factors for long-term morbidity and mortality. The same modelbuilding strategy was used for all outcomes: those variables with a univariate $P$ value of less than .25 were submitted for consideration to regression analysis by using stepwise selection to determine the independent multivariate predictors of each outcome.

\section{RESULTS}

\section{Clinical Status}

Fourteen years after the study's start, 40 patients aged 65 years or less ( $45 \%$ of enrolled patients) and 55 patients older than 65 years $(33 \%)$ are still actively being followed.

Three to 6 months after Mosaic bioprosthesis implantation, all younger patients and all but 1 older patient $(99 \%)$ were in NYHA class I or II. At their latest followup, $93 \%$ of the younger patients and $78 \%$ of the older patients were in NYHA class I or II.

At discharge, 75 (85\%) younger patients and $138(84 \%)$ older patients were in sinus rhythm. In addition, $6(7 \%)$ younger patients and $17(10 \%)$ older patients were in AF, $1(1 \%)$ older patient had heart block, and 7 (8\%) younger patients and $9(5 \%)$ older patients had a paced rhythm. At their latest follow-up, 30 (75\%) younger patients and 35 $(66 \%)$ older patients were still in sinus rhythm, $5(13 \%)$ younger patients and $14(26 \%)$ older patients were in $\mathrm{AF}$, and $5(12 \%)$ younger patients and $3(6 \%)$ older patients were paced. Over time, there was no difference in cardiac rhythm distribution between age groups.

Antithromboembolic medication use after 3 to 6 months of follow-up consisted of anticoagulant drug use (phenprocoumon and heparin) in $6(7 \%)$ younger patients and 22 $(14 \%)$ older patients, antiplatelet drug use (aspirin, ticlopidine, and clopidogrel) in 36 (42\%) younger patients and 91 $(58 \%)$ older patients, and no antithromboembolic medication in $44(51 \%)$ younger patients and $44(28 \%)$ older patients. At their latest follow-up, $8(20 \%)$ younger patients and $12(22 \%)$ older patients were using anticoagulant drugs, $21(53 \%)$ younger patients and $33(60 \%)$ older patients were using antiplatelet drugs, and $11(28 \%)$ younger patients and $10(18 \%)$ older patients were not using any antithromboembolic medication. Over time, antithromboembolic medication use significantly changed in favor of anticoagulant treatment $(P<.001)$, but there was no difference in treatment between age groups.

\section{Echocardiography}

Three to 6 months after Mosaic bioprosthesis implantation, transthoracic echocardiographic analysis revealed a mean SVG of $12.7 \pm 5.6 \mathrm{~mm} \mathrm{Hg}$ (range, $4.8-34.0 \mathrm{~mm} \mathrm{Hg}$ ) in the younger patients and $11.7 \pm 5.0 \mathrm{~mm} \mathrm{Hg}$ (range, 3.0-43.1 $\mathrm{mm} \mathrm{Hg}$ ) in the older patients. At their latest follow-up,
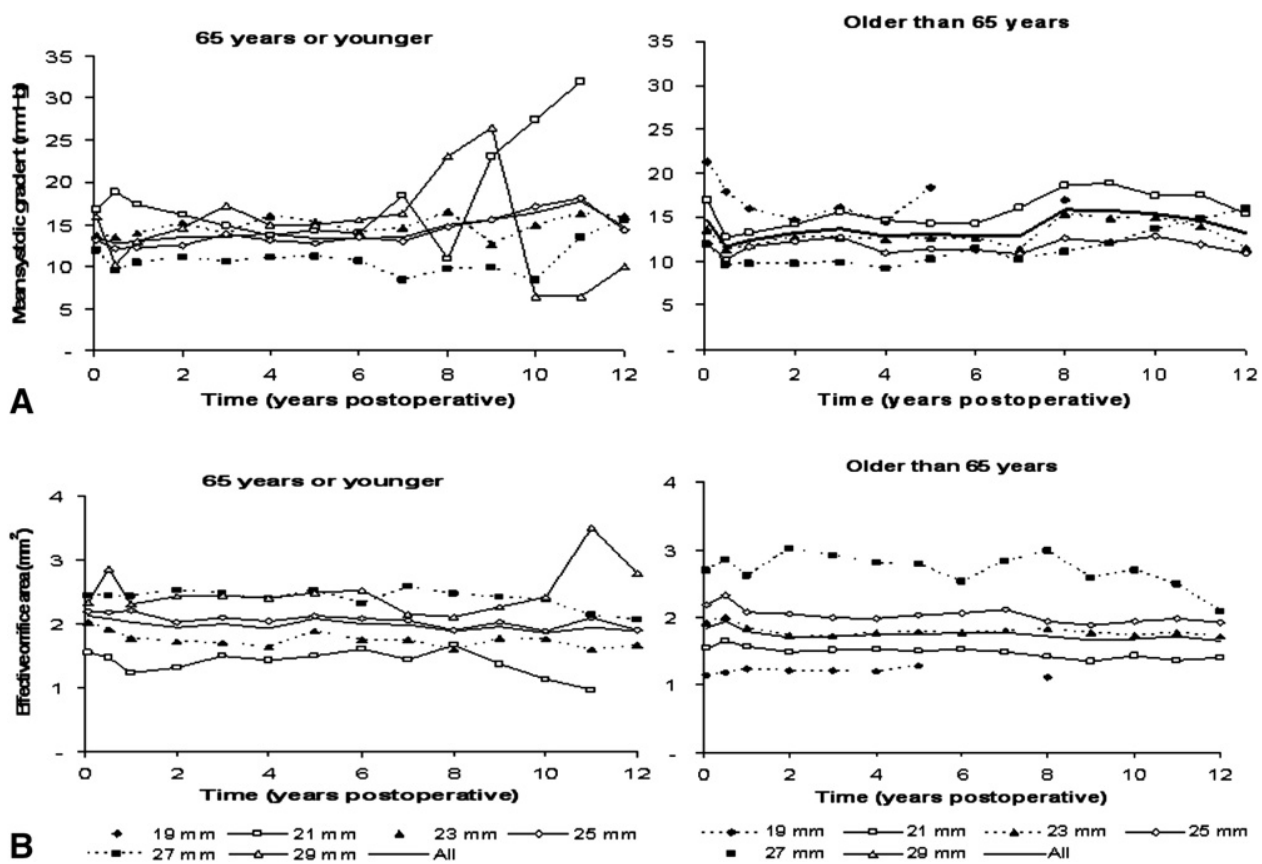

FIGURE 1. A, Mean systolic gradient over time in patients aged 65 years or younger and in patients older than 65 years (time effect: $P<.001$ ). B, Effective orifice area over time in patients aged 65 years or younger and in patients older than 65 years (time effect: $P<.001$; age group effect: $P<.001$ ). 
TABLE 2. Frequency of adverse events and actuarial freedom from valve-related adverse events 4,8 , and 12 years after aortic valve replacement in patients aged 65 years or less $(n=88,744.1$ late patient-years) and patients older than 65 years $(n=167,1209.4$ late patient-years $)$

\begin{tabular}{|c|c|c|c|c|c|c|c|c|c|c|}
\hline \multirow[b]{3}{*}{ Adverse event } & \multicolumn{5}{|c|}{$\leq 65 \mathrm{y}$} & \multicolumn{5}{|c|}{$>65 y$} \\
\hline & \multicolumn{2}{|r|}{ Late events } & \multicolumn{3}{|c|}{$\begin{array}{l}\text { Actuarial freedom } \\
\text { from event }(\% \pm \mathrm{SE})\end{array}$} & \multicolumn{2}{|r|}{ Late events } & \multicolumn{3}{|c|}{$\begin{array}{c}\text { Actuarial freedom } \\
\text { from event }(\% \pm \mathrm{SE})\end{array}$} \\
\hline & No. & $\% /$ patient-years & $4 y$ & $8 y$ & $12 y$ & No. & $\% /$ patient-years & $4 y$ & $8 y$ & $12 y$ \\
\hline $\begin{array}{c}\text { Structural valve } \\
\text { deterioration }\end{array}$ & 7 & 0.9 & 100.0 & 100.0 & $85.7 \pm 5.1$ & 2 & 0.2 & 100.0 & 100.0 & $98.5 \pm 1.5^{*}$ \\
\hline $\begin{array}{l}\text { Nonstructural valve } \\
\text { dysfunction }\end{array}$ & 2 & 0.3 & $97.7 \pm 1.6$ & $97.7 \pm 1.6$ & $97.7 \pm 1.6$ & 2 & 0.2 & $98.8 \pm 0.9$ & $98.8 \pm 0.9$ & $94.3 \pm 4.5$ \\
\hline Major paravalvular leak & 0 & 0.0 & 100.0 & 100.0 & 100.0 & 0 & 0.0 & $99.4 \pm 0.6$ & $99.4 \pm 0.6$ & $99.4 \pm 0.6$ \\
\hline Mismatch & 2 & 0.3 & $97.7 \pm 1.6$ & $97.7 \pm 1.6$ & $97.7 \pm 1.6$ & 1 & 0.1 & $99.4 \pm 0.6$ & $99.4 \pm 0.6$ & $99.4 \pm 0.6$ \\
\hline Pannus formation & 0 & 0.0 & 100.0 & 100.0 & $95.6 \pm 2.4$ & 1 & 0.1 & 100.0 & 100.0 & 100.0 \\
\hline Endocarditis & 8 & 1.1 & $96.4 \pm 2.0$ & $95.0 \pm 2.5$ & $87.5 \pm 4.3$ & 2 & 0.2 & $99.4 \pm 0.6$ & $98.5 \pm 1.1$ & $98.5 \pm 1.1 \dagger$ \\
\hline Thromboembolism & 4 & 0.5 & $97.6 \pm 1.7$ & $96.0 \pm 2.3$ & $94.1 \pm 3.0$ & 13 & 0.9 & $94.1 \pm 1.9$ & $92.4 \pm 2.2$ & $89.5 \pm 3.0$ \\
\hline Permanent neurologic event & 1 & 0.1 & 100.0 & 100.0 & $98.0 \pm 2.0$ & 3 & 0.2 & $97.4 \pm 1.3$ & $97.4 \pm 1.3$ & $97.4 \pm 1.3$ \\
\hline Transient neurologic event & 0 & 0.0 & 100.0 & 100.0 & 100.0 & 5 & 0.4 & $97.3 \pm 1.4$ & $96.4 \pm 1.6$ & $94.8 \pm 2.2$ \\
\hline Peripheral embolic event & 1 & 0.1 & $98.8 \pm 1.2$ & $98.8 \pm 1.2$ & $98.8 \pm 1.2$ & 0 & 0.0 & 100.0 & 100.0 & 100.0 \\
\hline Acute myocardial infarction & 1 & 0.1 & 100.0 & $98.4 \pm 1.6$ & $98.4 \pm 1.6$ & 0 & 0.0 & 100.0 & 100.0 & 100.0 \\
\hline Valvular thrombosis & 1 & 0.1 & $98.8 \pm 1.2$ & $98.8 \pm 1.2$ & $98.8 \pm 1.2$ & 3 & 0.2 & $99.4 \pm 0.6$ & $98.6 \pm 1.0$ & $97.1 \pm 1.8$ \\
\hline Hemolysis & 0 & 0.0 & 100.0 & 100.0 & 100.0 & 0 & 0.0 & 100.0 & 100.0 & 100.0 \\
\hline Major hemorrhages & 3 & 0.4 & $97.7 \pm 1.6$ & $96.2 \pm 2.2$ & $96.2 \pm 2.2$ & 4 & 0.3 & $97.4 \pm 1.3$ & $96.5 \pm 1.6$ & $96.5 \pm 1.6$ \\
\hline Valve-related reoperation & 20 & 2.7 & $94.1 \pm 2.6$ & $89.9 \pm 3.4$ & $68.9 \pm 6.0$ & 9 & 0.7 & $98.1 \pm 1.1$ & $96.4 \pm 1.6$ & $89.3 \pm 4.8 \dagger$ \\
\hline Explantation & 20 & 2.7 & $94.1 \pm 2.6$ & $89.9 \pm 3.4$ & $68.9 \pm 6.0$ & 9 & 0.7 & $98.1 \pm 1.1$ & $96.4 \pm 1.6$ & $89.3 \pm 4.8 \dagger$ \\
\hline Death & 17 & 2.3 & $95.3 \pm 2.3$ & $84.1 \pm 4.2$ & $73.5 \pm 6.5$ & 45 & 3.7 & $87.1 \pm 2.6$ & $72.4 \pm 3.9$ & $60.8 \pm 5.1^{*}$ \\
\hline Cardiac death & 1 & 0.1 & 100.0 & $98.3 \pm 1.7$ & $98.3 \pm 1.7$ & 9 & 0.7 & $95.0 \pm 1.7$ & $92.3 \pm 2.3$ & $91.1 \pm 2.6^{*}$ \\
\hline Noncardiac death & 8 & 1.1 & $97.5 \pm 1.7$ & $90.5 \pm 3.5$ & $87.6 \pm 4.4$ & 22 & 1.8 & $94.1 \pm 1.9$ & $87.2 \pm 3.1$ & $76.5 \pm 5.2$ \\
\hline Valve-related death & 1 & 0.1 & 100.0 & 100.0 & $98.1 \pm 1.9$ & 2 & 0.2 & $99.3 \pm 0.7$ & $98.4 \pm 1.1$ & $98.4 \pm 1.1$ \\
\hline Unexplained death & 7 & 0.9 & $97.7 \pm 1.6$ & $94.6 \pm 2.6$ & $87.0 \pm 5.9$ & 12 & 1.0 & $98.1 \pm 1.1$ & $91.5 \pm 2.6$ & $88.7 \pm 3.2$ \\
\hline
\end{tabular}

$S E$, Standard error. $* P<.05$ and $\dagger P<.01, \log$-rank test.

mean SVG had increased to $17.0 \pm 8.6 \mathrm{~mm} \mathrm{Hg}$ (range, 6.0 $50.0 \mathrm{~mm} \mathrm{Hg}$ ) and $14.7 \pm 6.6 \mathrm{~mm} \mathrm{Hg}$ (range, $5.0-31.0 \mathrm{~mm}$ $\mathrm{Hg}$ ), respectively. Mean SVG increased significantly over time $(P<.001$; Figure $1, A)$, without a significant difference between age groups.

EOA values were $2.1 \pm 0.5$ and $1.9 \pm 0.6 \mathrm{~cm}^{2}$ in younger and older patients 3 to 6 months after implantation. Over time, EOA values decreased significantly to $1.8 \pm 0.5$ and $1.6 \pm 0.5 \mathrm{~cm}^{2}$ at latest follow-up $(P<.001$; Figure $1, B)$. Overall, EOA values were significantly higher in younger compared with older patients $(P<.001)$.

Transvalvular regurgitation was mild or less in more than $95 \%$ of the patients over time and comparable between the 2 groups (Figure E1). However, in both groups the percentage of patients with no regurgitation significantly decreased over time, whereas the incidence of trivial and mild regurgitation increased over time $(P<.001)$.

\section{Valve-Related Adverse Events}

Linearized rates for late valve-related adverse events and actuarial freedom from valve-related adverse event percentages after 4, 8, and 12 years of Mosaic bioprosthesis implantation are summarized in Table 2 for younger and older patients.
SVD. No early cases of SVD were found. During followup, 7 younger patients and 2 older patients were given diagnoses of SVD, and their valves were subsequently explanted. Freedom from SVD over time was significantly lower in the younger patients $(P<.05$; Figure 2$)$. In the younger group SVD was combined with isolated aortic valve regurgitation in 2 cases, isolated stenosis in 2 cases, and combined regurgitation and stenosis in 2 cases. Explant analysis showed moderate to extensive mineralization at 1 or more commissures in 4 valves, extensive leaflet mineralization, and thrombotic/vegetative-appearing material in the right and left coronary cusp in 1 valve and moderately thick, thrombotic-appearing material in all cusps in the last valve. In the older group SVD was combined with regurgitation in 1 patient and combined regurgitation and stenosis in the other patient. Explant analysis of both explanted valves showed moderate to extensive mineralization at 1 or more commissures.

Nonstructural valve dysfunction. One $(0.6 \%)$ early case of nonstructural valve dysfunction, a paravalvular leak, was diagnosed in a younger patient on day 6 . The valve was explanted on day 106. Four late cases of nonstructural valve dysfunction occurred, 2 cases per age group, and these were diagnosed by means of echocardiographic analysis. 


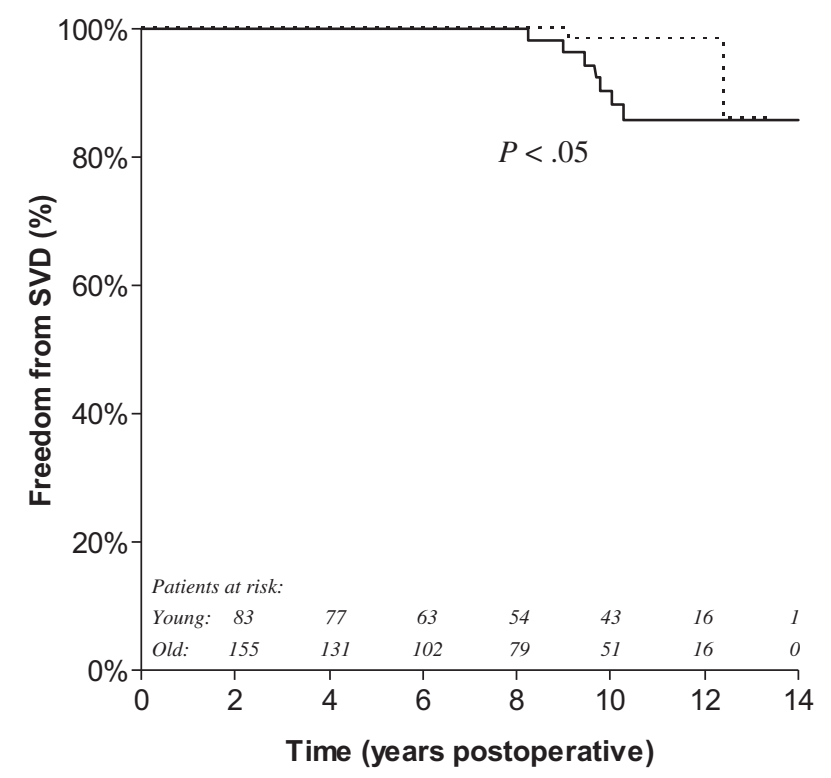

FIGURE 2. Freedom from structural valve deterioration (SVD) over time in patients aged 65 years or younger (solid line) and in patients older than 65 years (dashed line).

In the first younger patient the valve was explanted due to patient-bioprosthesis mismatch on day 34 . In the second younger patient mismatch was diagnosed on day 139 . The valve was explanted due to valvular thrombosis 2.4 years after implantation. In the first older patient the mismatched Mosaic bioprosthesis, as diagnosed on day 135, was still in place until his death from pneumonia 6.9 years after implantation. In the second older patient nonstructural valve dysfunction caused by pannus formation was diagnosed, and the valve was explanted 11.3 years after implantation. Freedom from nonstructural valve dysfunction was similar in younger and older patients.

Endocarditis. No early and 10 late cases of endocarditis were observed, 8 cases in the younger group (range, $0.7-$ 9.8 years after implantation) and 2 cases in the older group (1.7 and 5.2 years after implantation, respectively). In the younger group Streptococcus species was isolated in 3 patients, whereas no bacterium was reported in the other 5 patients. In the older group Streptococcus species was isolated in 1 patient and Enterococcus species was isolated in the other patient. All patients had their infected valves explanted. Freedom from endocarditis was significantly lower in the younger group $(P<.01$, Table 2$)$.

Thromboembolism. Two (1.2\%) early cases of thromboembolism occurred, both in the older group. One patient was considered to have paroxysmal $\mathrm{AF}$, and this patient had a stroke during heparin treatment on postoperative day 7 . The other patient was considered to have permanent $\mathrm{AF}$, and this patient had a transient ischemic attack on postoperative day 13. In addition, 4 late thromboembolic events occurred in the younger group (range, 2.1-9.3 years after implantation), and 13 events occurred in the older group (range, 0.2-9.1 years after implantation). In the younger group thromboembolic events involved 1 permanent neurologic event, 1 peripheral thromboembolic event, 1 myocardial infarction, and 1 valvular thrombosis. In the older group thromboembolic events involved 3 permanent neurologic events, 5 transient ischemic events, and 3 thrombosed valves. In the younger patient valvular thrombosis was diagnosed during aspirin treatment 2.4 years after implantation. The thrombosed valve was replaced with a mechanical valve. Analysis of the explanted valve showed extensive thrombosis but no signs of cuspal degeneration, calcification, or infection. In the older patients the first case of valvular thrombosis was diagnosed on postoperative day 87. Phenprocoumon had been discontinued on day 24 because of recurrent hemorrhage. The thrombosed valve was replaced with a Hancock II bioprosthesis that thrombosed during the early postoperative course as well and was replaced with a mechanical valve. The other 2 cases of valvular thrombosis were diagnosed during aspirin treatment 5.0 and 9.0 years after implantation, respectively. The thrombosed valves were replaced with a mechanical valve and a second Mosaic bioprosthesis. Explant analysis of all 3 Mosaic valves and the Hancock II valve revealed thrombotic-appearing material without signs of calcification and infection in all 4 valves. Freedom from thromboembolism or any of its subcategories was similar between age groups.

Major hemorrhages. In both age groups 1 early case of major hemorrhage occurred ( $1.1 \%$ vs $0.6 \%)$ : a severe cardiac tamponade 23 days after surgical intervention in a younger patient and a severe epistaxis 24 days after surgical intervention in an older patient. Both events occurred with phenprocoumon treatment. Furthermore, there were 3 late major hemorrhages (range, 0.3-5.8 years after implantation) observed in 2 younger patients: a gastrointestinal bleed in 1 patient and both a nonacute pleural effusion on postoperative day 100 and severe hematoma of the thigh after an accident 5.8 years after Mosaic bioprosthesis implantation in the second patient. Four late major hemorrhages were observed in 4 older patients (range, 0.4-5.8 years after implantation): cerebral hematoma in 2 patients and gastrointestinal hemorrhage in 2 patients. There was no difference in freedom from major hemorrhage between age groups.

Hemolysis. No cases of hemolysis were reported for either group.

Valve-related reoperation and explantation. No early Mosaic bioprosthesis-related reoperations and explantations occurred. In the younger group 20 late valve-related reoperations occurred (range, 0.1-10.9 years after implantation), all resulting in explantation. Reasons for explantation were endocarditis in 8 patients, SVD in 7 patients, nonstructural valve dysfunction in 1 patient, and valvular thrombosis in 1 patient. In addition, 3 valves were replaced 
incidentally because of ascending aortic aneurysm. One patient died after reoperation for endocarditis. In the older group 9 valves were explanted 0.2 to 12.4 years after implantation. Reasons for explantation were valvular thrombosis in 3 patients, endocarditis in 2 patients, SVD in 2 patients, and nonstructural valve dysfunction in 2 patients. Freedoms from valve-related reoperation and explantation were significantly lower in younger patients $(P<.01)$.

\section{Survival}

No younger but $3(1.8 \%)$ older patients died within 30 days after surgical intervention or before discharge. All 3 deaths were classified as cardiac deaths. Causes of death were hypertrophic obstructive cardiomyopathy with left ventricular outlet obstruction on postoperative day 3 , acute pericardial tamponade caused by aortic dissection and perforation on postoperative day 13 , and biventricular heart failure on postoperative day 36 . In the younger group 17 late deaths occurred: 1 cardiac death, 8 noncardiac deaths, 1 valve-related death, and 7 unexplained deaths. The valverelated death was a 49-year old man who died 8.5 years after implantation because of low output syndrome after Mosaic explantation for endocarditis. In the older group 45 late deaths occurred: 9 cardiac deaths, 22 noncardiac deaths, 2 valve-related deaths, and 12 unexplained deaths. The first valve-related death consisted of a 66-year old man with a cerebral hemorrhage while taking phenprocoumon for permanent AF who had septicemia after a relieving operation 5.8 years after implantation. The second valverelated death was a 68-year-old man who died from heart failure 2.7 years after implantation after having a stroke.
No autopsy was performed in any of these patients. Freedom from valve-related or unexplained death at latest follow-up was similar in younger and older patients $(78.8 \% \pm 8.4 \%$ vs $87.3 \% \pm 3.2 \%$ [older patients]; Figure E2 and Table 2).

\section{DISCUSSION}

This single-center study compares the clinical performance of the Mosaic bioprosthesis implanted in patients aged 65 years or less with that of patients older than 65 years.

The data of annual prospective standardized echocardiographic follow-up presented here are unique to this study cohort. Mean SVG, EOA, and transvalvular regurgitation significantly changed over time in both age groups. However, the magnitude of the changes did not affect the hemodynamic performance of the Mosaic valve and was comparable with data reported in earlier Mosaic series ${ }^{8,16,17}$ or other frequently implanted tissue valves. ${ }^{18-20}$ EOA values were significantly higher in younger patients. This can be explained by the larger valve size implanted in this group.

In our study population 7 younger and 2 older patients had SVD, resulting in a significantly lower freedom from SVD in the younger patients (after 12 years, $85.7 \% \pm 5.1 \%$ vs $98.5 \% \pm 1.5 \%$; at latest follow-up, $85.6 \% \pm 5.1 \%$ vs $86.2 \% \pm 11.6 \%$; Figure 2). Other studies showed a clear age effect for patients younger and older than 65 years of age as well. Aupart and colleagues 5 reported a 13-year freedom from SVD of approximately $87 \%$ in patients less than 60 years of age, $94 \%$ in patients aged 60 to 70 years, and approximately $97 \%$ in patients older than 70 years after Perimount implantation. Reported 15-year freedom from SVD rates were $75 \%$ versus $100 \%{ }^{6}$ and $76 \%$ versus

TABLE 3. Risk ratio and $95 \%$ CI for independent predictors of morbidity and mortality in all patients, patients aged 65 years or less, and patients older than 65 years

\begin{tabular}{|c|c|c|c|c|c|c|c|c|c|}
\hline \multirow[b]{2}{*}{ Risk factor } & \multicolumn{3}{|c|}{ All $(n=255)$} & \multicolumn{3}{|c|}{$\leq 65$ y $(n=88)$} & \multicolumn{3}{|c|}{$\geq 65$ y $(n=167)$} \\
\hline & Risk ratio & $95 \%$ CI & $P$ value & Risk ratio & $95 \%$ CI & $P$ value & Risk ratio & $95 \%$ CI & $P$ value \\
\hline \multicolumn{10}{|l|}{ Structural valve disease } \\
\hline Age (per 5-y increase) & 0.64 & $0.50-0.84$ & .011 & 0.71 & $0.51-0.99$ & .047 & - & - & NS \\
\hline \multicolumn{10}{|c|}{ Nonstructural valve dysfunction } \\
\hline NYHA class IV & - & - & NS & 18.6 & $1.16-298$ & .039 & - & - & NS \\
\hline \multicolumn{10}{|l|}{ Endocarditis } \\
\hline Age (per 5-y increase) & 0.71 & $0.55-0.90$ & .006 & - & - & NS & - & - & NS \\
\hline Active endocarditis & 9.14 & $1.66-50.4$ & .011 & 12.8 & $2.55-64.5$ & .002 & - & - & NS \\
\hline Thromboembolism & - & - & NS & - & - & NS & - & - & NS \\
\hline Valvular thrombosis & - & - & NS & - & - & NS & - & - & NS \\
\hline \multicolumn{10}{|l|}{ Valve explantation } \\
\hline Age (per 5-y increase) & 0.73 & $0.63-0.85$ & .000 & 0.68 & $0.54-0.85$ & .000 & - & - & NS \\
\hline \multicolumn{10}{|l|}{ Death } \\
\hline Age (per 5-y increase) & 1.31 & $1.08-1.60$ & .007 & - & - & NS & - & - & NS \\
\hline Current smoker & 2.07 & $1.16-3.69$ & .014 & 3.55 & $1.35-9.35$ & .010 & - & - & NS \\
\hline Male sex & 1.83 & $1.03-3.25$ & .038 & - & - & NS & - & - & NS \\
\hline NYHA class IV & - & - & NS & 4.84 & $1.06-22.1$ & .042 & - & - & NS \\
\hline Preoperative AF & - & - & NS & - & - & NS & 3.00 & $1.05-8.57$ & .040 \\
\hline
\end{tabular}

$C I$, Confidence interval; $N Y H A$, New York Heart Association; $A F$, atrial fibrillation. 


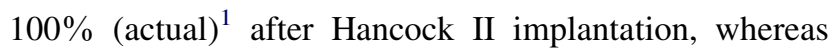
15-year freedom from SVD for the Carpentier-Edwards Supraannular Valve was $54 \%$ versus $92 \%{ }^{6}$ Compared with the other studies, the Mosaic bioprosthesis seems to have a similar to higher durability in patients aged 65 years or less, but additional studies and longer follow-up are necessary to verify this. For older patients, the Mosaic bioprosthesis has similar durability as other valves when looking at the 12-year freedom from SVD value, but it tends to do worse when referring to the 13-year value. However, because of the $12 \%$ standard error on this value, we cannot make valid assumptions at this follow-up interval. Independent of age, freedom from SVD for other bioprosthetic valves in the aortic position ranged from $70 \%$ to $85 \%$ after 15 years of implantation, ${ }^{1,6,21,22}$ suggesting that the Mosaic bioprosthesis' SVD rates are on the upper range of reported values. In line with the literature, ${ }^{1,6}$ multivariate regression analysis showed that an increase in age had an independent protective effect on SVD development in both the complete study group and patients aged 65 years or less (both $P<.05$ ), whereas this effect had disappeared in patients older than 65 years (Table 3 ). This was probably due to the limited number of SVD cases in the elderly.

The first case of SVD in our group occurred after 8.4 years of implantation in the younger group and after 9.1 years of implantation in the older group (Figure 2). In comparison, SVD was most commonly reported after approximately 5 years of implantation for the Intact valve,$^{23}$ the Hancock II valve, ${ }^{1,6,21}$ the Mosaic valve, ${ }^{24}$ and the Carpentier-Edwards pericardial bioprosthesis. ${ }^{3-5}$

Eight younger patients and 2 older patients had endocarditis, resulting in a significantly lower freedom from endocarditis rate in the young $(88 \%$ vs $99 \%)$. This is in line with Aupart and colleagues, ${ }^{5}$ who showed that after 20 years of follow-up, $6 \%$ of the patients younger than 60 years of age, $3 \%$ of the patients aged 60 to 70 years, and $1 \%$ of the patients older than 70 years had endocarditis. Multivariate regression analysis showed that an increase in age had an independent protective effect on the development of endocarditis in the complete study group $(P<.01)$. In addition, preoperative active endocarditis was a significant risk factor for endocarditis after Mosaic implantation both in the complete study group $(P<.05)$ and in patients aged 65 years or younger $(P<.01$, Table 3$)$. Because we only have a limited number of endocarditis cases in patients older than 65 years, this might have hampered our efforts to find any independent effects.

The overall freedom from infective endocarditis after Mosaic bioprosthesis implantation is similar to that reported for other stented porcine and pericardial valves, such as the Hancock II valve, ${ }^{1,21}$ the Perimount valve, ${ }^{18}$ the Biocor valve, ${ }^{25}$ the Intact valve, ${ }^{23}$ and the CarpentierEdwards standard prosthesis, ${ }^{4}$ ranging from $91 \%$ to $98 \%$.
Because all valves with SVD and endocarditis were explanted and these rates were higher in the younger group, it is obvious that the incidence of reoperation and explantation was also significantly higher in patients aged 65 years of younger. Freedom from explantation at latest follow-up was $68.9 \% \pm 6.0 \%$ and $77.9 \% \pm 11.3 \%$ in younger and older patients, respectively. This is in line with explantation rates of other valves. Rizzoli and associates ${ }^{21}$ reported a $15-$ year freedom from explantation in patients receiving the Hancock II valve of $56 \%$ for patients aged less than 60 years and $90 \%$ for patients 60 years or older. Chan and coworkes $^{7}$ reported a 15-year freedom from explantation in patients with bioprosthetic valves of $45 \%$ in patients aged 51 to 60 years, $78 \%$ in patients aged 61 to 70 years, and $93 \%$ in patients older than 70 years. Others also showed a significant inverse relationship between age of implantation and incidence of explantation in patients receiving the Hancock II valve ${ }^{1}$ and the Carpentier-Edwards standard valve. ${ }^{4}$ In line with the literature, multivariate regression analysis showed that an increase in age had an independent protective effect on valve explantation in both the complete study group and patients aged 65 years or less (both $P<.001$ ), whereas this effect disappeared in the elderly (Table 3).

Freedom from nonstructural valve dysfunction was comparable between the groups ( $98 \%$ vs $94 \%$ ). Barratt-Boyes and colleagues ${ }^{23}$ reported an age-independent 10-year freedom from nonstructural valve dysfunction of $95 \%$ for aortic and mitral valves combined, primarily because of perivalvular leaks. Our series consisted of 1 paravalvular leak, 3 mismatched valves ( 1 of which had to be explanted for that reason), and 1 valve with pannus formation. Multivariate regression analysis showed that patients aged 65 years or less with an NYHA class of IV had a significantly higher chance of nonstructural valve dysfunction $(P<.05)$, whereas this effect was not present in the complete group and in patients older than 65 years (Table 3 ).

Four thromboembolic events occurred in the younger group, and 13 such events occurred in the older group, but there was no significant difference between age groups in the incidence of thromboembolism or any of its subcategories (Table 2). Multivariate regression analysis also did not show any independent risk factors for thromboembolic events (Table 3). Aupart and colleagues ${ }^{5}$ also reported no age effect after Perimount implantation. In the younger group 1 case of valvular thrombosis occurred without obvious cause. In the older group 3 cases of valvular thrombosis occurred. The first patient was a 73-year-old woman who, after explantation of the Mosaic bioprosthesis on postoperative day 87, was given a diagnosis of a congenital antithrombin deficiency. The residual antithrombin III activity of only $20 \%$ can be considered the primary cause of this thrombosis. The second patient was a 67-year-old man who had valvular thrombosis 5 years after implantation. Early postoperatively, this patient had acute 
heparin-induced thrombocytopenia type II, as well as acquired antithrombin III deficiency that had to be treated with recombinant hirudin (Lepirudin; 1; Pharmion, Boulder, Colo). The overlapping treatment with phenprocoumon had to be stopped early because of a gastrointestinal hemorrhage. Intraoperative findings and histological investigation of the explanted Mosaic bioprosthesis supported the theory of heparin-induced thrombocytopenia. For the last case of valvular thrombosis, there was no obvious explanation. In the literature the overall incidence of bioprosthesis thrombosis is comparable with ours, although freedom from valvular thrombosis is not frequently given. ${ }^{1,2,21,23}$ Multivariate regression analysis did not find an independent risk factor for valvular thrombosis (Table 3).

Our survival rate of $61 \%$ (vs $68 \%$ ) in the elderly favors that of David and associates, ${ }^{1}$ who showed a 15 -year survival rate after Hancock II implantation of $65 \%$ in patients aged less than 65 years and $30 \%$ in patients 65 years or older. Multivariate regression analysis showed that increase in age $(P<.01)$, being a preoperative current smoker, and male sex (both $P<.05$ ) were independent risk factors for death in the overall group. In patients 65 years of age or less, being a preoperative current smoker $(P=0.01)$ and NYHA class IV $(P<.05)$ were independent predictors for death, whereas in patients older than 65 years, preoperative $\mathrm{AF}$ was an independent predictor for death $(P<.05$, Table $3)$. Interestingly, there is quite an overlap with the mortality risk factors found by David and associates, ${ }^{1}$ who also showed an independent effect for age and NYHA class IV in all patients and age, male sex, and preoperative AF in patients without concomitant coronary artery bypass grafting. In addition, David and associates showed that coronary artery disease, active endocarditis, and left ventricular ejection fraction of less than $40 \%$ were independent risk factors for death. The first 2 factors were not significant in our analysis, whereas the latter was not included in our analysis. Freedom from valve-related or unexplained death was comparable between groups $(79 \%$ vs $89 \%)$. However, Chan and coworkers ${ }^{7}$ showed that freedom from valverelated death after 15 years of bioprosthesis implantation was lower in older patients: $92 \%$ in patients aged 51 to 60 years, $83 \%$ in patients aged 61 to 70 years, and $78 \%$ in patients older than 70 years. Two Hancock II studies show an overall freedom from valve-related and unexplained death rate of $71 \%$ to $92 \%$ after 15 years, which is in line with our findings. 1,21

In conclusion, the Mosaic bioprosthesis shows comparable hemodynamic performance over time in younger and older patients. In patients aged 65 years or less, the incidence of SVD, endocarditis, and valve-related reoperation and explantation is higher compared with that seen in patients older than 65 years. The incidence of SVD in the younger patients tends to be lower compared with that seen in the literature. However, continued clinical follow- up is required to examine whether the durability of the Mosaic bioprosthesis is similar or better compared with that of other bioprosthetic valves.

\section{References}

1. David TE, Ivanov J, Armstrong S, Feindel CM, Cohen G. Late results of heart valve replacement with the Hancock II bioprosthesis. J Thorac Cardiovasc Surg. 2001;121:268-78.

2. Magilligan DJ, Lewis JW, Stein P, Alam M. The porcine bioprosthetic heart valve: experiences at 15 years. Ann Thorac Surg. 1989;48:324-30.

3. Pelletier LC, Carrier M, Leclerc Y, Dyrda I. The Carpentier-Edwards pericardial bioprosthesis: clinical experience with 600 patients. Ann Thorac Surg. 1995; 60(suppl):S297-302.

4. Bernal JM, Rabasa JM, Lopez R, Nistal JF, Muniz R, Revuelta JM. Durability of the Carpentier-Edwards porcine bioprosthesis: Role of age and valve position. Ann Thorac Surg. 1995;60(suppl):S248-52.

5. Aupart MR, Mirza A, Meurisse YA, Sirinelli AL, Neville PH, Marchand MA Perimount pericardial bioprosthesis for aortic calcified stenosis: 18-year experience with 1,133 patients. J Heart Valve Dis. 2006;15:768-76.

6. Jamieson WR, David TE, Feindel CMS, Miyagishima RT, Germann E. Performance of the Carpentier-Edwards SAV and Hancock-II porcine bioprostheses in aortic valve replacement. J Heart Valve Dis. 2002;11 424-30

7. Chan V, Jamieson WR, Germann E, Chana F, Miyagishima RT, Burr LH, et al. Performance of bioprostheses and mechanical prostheses assessed by composites of valve-related complications to 15 years after aortic valve replacement. $J$ Thorac Cardiovasc Surg. 2006;131:1267-73.

8. Fradet G, Bleese N, Busse E, Jamieson E, Raudkivi P, Goldstein J, et al. The Mosaic valve clinical performance at seven years: results from a multicenter prospective clinical trial. J Heart Valve Dis. 2004;13:239-47.

9. Carpentier A, Lemaigre G, Robert L, Carpentier S, Dubost C. Biological factors affecting long-term results of valvular heterografts. J Thorac Cardiovasc Surg. 1969;58:467.

10. Vesely I. Analysis of the Medtronic Intact bioprosthesis valve. Effects of zeropressure fixation. J Thorac Cardiovasc Surg. 1991;101:90-9.

11. Duarte IG, MacDonald MJ, Cooper WA, Schmarkey SL, Gott JP, Brown WM 3rd, et al. In vivo hemodynamic, histologic, and antimineralization characteristics of the Mosaic bioprosthesis. Ann Thorac Surg. 2001;71:92-9.

12. Girardot MN, Girardot JM, Schoen FJ. Alpha-amino oleic acid, a new compound prevents calcification of bioprosthetic heart valves. Trans Soc Biomater. 1991;14: 114-6.

13. Walther T, Falk V, Diegeler A, Rauch T, Weigl C, Gummert J, et al. Effectiveness of different anticalcification treatments for stentless aortic bioprosthesis. Thorac Cardiovasc Surg. 1999;47:23-5.

14. Edmunds LH, Clark RE, Cohn LH, Grunkemeier GL, Miller DC, Wiesel RD Guidelines for reporting morbidity and mortality after cardiac valvular operations. Ann Thorac Surg. 1996;62:932-5.

15. Peto R, Pike MC, Armitage P, Breslow NE, Cox DR, Howard SV, et al Design and analysis of randomized clinical trials requiring prolonged observation of each patient. II. Analysis and examples. Br J Cancer. 1977; 35:1-39.

16. Jamieson WRE, Janusz MT, MacNab J, Henderson C. Hemodynamic comparison of second and third generation stented bioprostheses in aortic valve replacement. Ann Thorac Surg. 2001;71:282-4.

17. Wong SP, Legget ME, Greaves SC, Barratt-Boyes BG, Milsom FP, Raudkivi PJ. Early experience with the mosaic bioprosthesis: a new generation porcine valve. Ann Thorac Surg. 2000;69:1846-50.

18. Frater RW, Furlong P, Cosgrove DM, Okies JE, Colburn LQ, Katz AS, et al. Long term durability and patient functional status of the Carpentier-Edwards Perimount pericardial bioprosthesis in the aortic position. J Heart Valve Dis. 1998; 7:48-53.

19. David TE, Armstrong S, Sun Z. Clinical and hemodynamic assessment of the Hancock II bioprosthesis. Ann Thorac Surg. 1992;54:661-7.

20. Jamieson WR, Janusz MT, Burr LH, Ling H, Miyagishima RT, Germann E. Carpentier-Edwards supraannular porcine bioprosthesis: Second-generation prosthesis in aortic valve replacement. Ann Thorac Surg. 2001;71:224-7.

21. Rizzoli G, Mirone S, Ius P, Polesel E, Bottio T, Salvador L, et al. Fifteen-year results with the Hancock II valve: a multicenter experience. J Thorac Cardiovasc Surg. 2006;132:602-9. 
22. Jamieson WR, Rosado LJ, Munro AI, Gerein AN, Burr LH, Miyagishima RT, et al. Carpentier-Edwards standard porcine bioprosthesesprimary tissue failure (structural valve deterioration) by age groups. Ann Thorac Surg. 1988;46:155-62.

23. Barratt-Boyes BG, Jaffe WM, Whitlock RM. The Medtronic intact porcine valve: Ten-year clinical review. J Thorac Cardiovasc Surg. 1998;116:1005-14.
24. Rieß Ch-F, Bader R, Cramer E, Hansen L, Kleijnen B, Wahl G, et al. Hemodynamic performance of the Medtronic Mosaic porcine bioprosthesis up to ten years. Ann Thorac Surg. 2007;83:1310-8.

25. Myken PS, Caidahl K, Larsson S, Berggren HE. 10-year experience with the Biocor porcine bioprosthesis in the aortic position. J Heart Valve Dis. 1994;3: 648-56. 


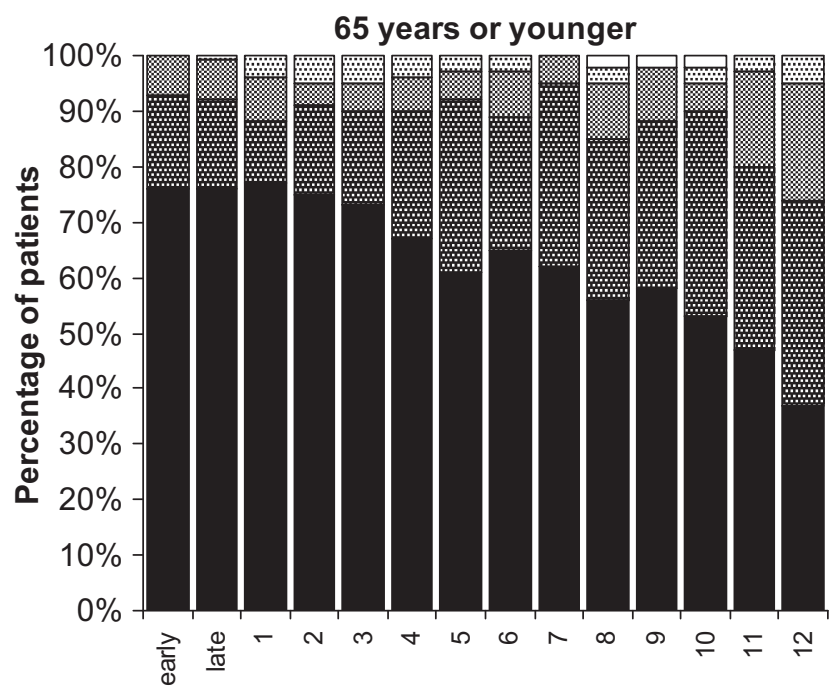

Time (years postoperative)

$\begin{array}{lll}\text { none } & \text { : trivial } & \text { mild } \\ \text { 圈 moderate } & \quad \text { mod-severe } & \square \text { severe }\end{array}$

FIGURE E1. Mosaic bioprosthesis regurgitation over time in patients aged 65 years or younger and in patients older than 65 years (time effect: $P<.001)$.

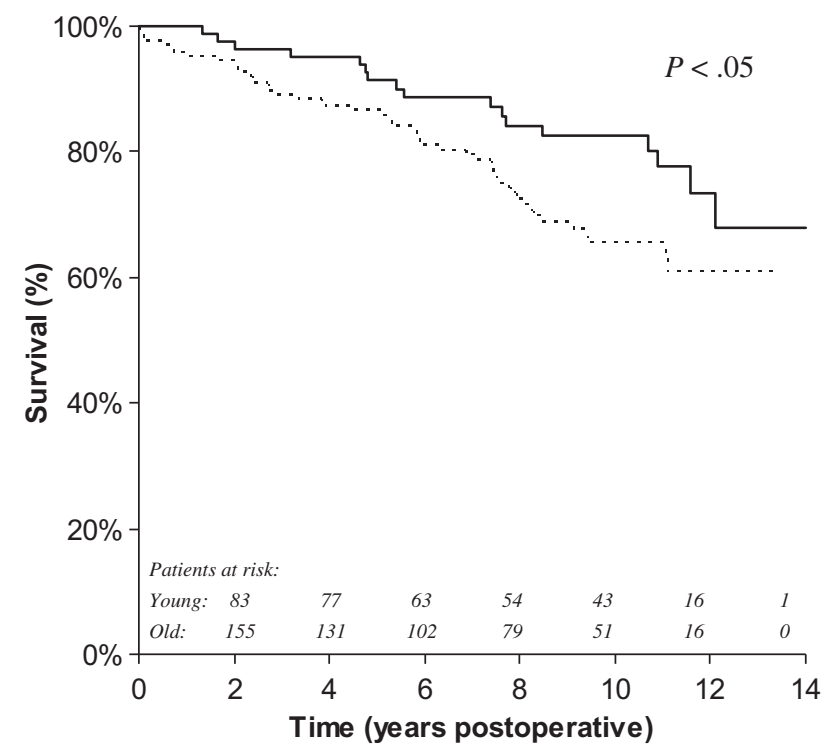

FIGURE E2. Survival over time in patients aged 65 years or younger (solid line) and in patients older than 65 years (dashed line). 